\title{
Os 15 anos da Linha de Estudos Epistemológicos e Didáticos em Educação Física no cinquentenário do Centro de Educação Física e Desportos da UFSM
}

\author{
15 years of Epistemological Studies and Didactics in Physical Education Line in the 50th \\ anniversary of Physical Education and Sports Center at UFSM
}

\section{Los 15 años de la Línea de Estudios Epistemológicos y Didáctica en Educación Física en el 50 aniversario del Centro de Educación Física y Deportes de la UFSM}

\author{
Gislei José Scapin ${ }^{\mathrm{I}}$, Gabriel Vielmo Gomes ${ }^{\mathrm{II}}$, Maristela da Silva Souza ${ }^{\mathrm{III}}$
}

\begin{abstract}
Resumo
Objetivamos descrever e situar a Linha de Estudos Epistemológicos e Didáticos em Educação Física durante seus 15 anos de existência no interior dos 50 anos do CEFD/UFSM. Em específico, descreveremos seus objetivos e seu histórico, bem como os pressupostos teóricos e pedagógicos que balizam suas atividades. Essas se constituem em consonância com a tríade universitária: pesquisa, extensão e ensino, à luz dos aportes teóricos do Materialismo Histórico e Dialético, da Pedagogia Histórico-Crítica, da Pedagogia Crítico-Superadora e da Cultura Corporal no embate às proposições irracionalistas e relativistas das teses pós-modernas que permeiam a área na contemporaneidade. Nessa direção, as ações da Linha, manifestadas de maneira política e científica, comprometidas com valores socialistas, são capazes de transformação humana e social, pois o conteúdo dessa mudança alicerça-se no conhecimento científico objetivado numa nova prática social.
\end{abstract}

Palavras-chave: Educação Física; Cultura Corporal; Materialismo Histórico

\begin{abstract}
We aim to describe and situate the Epistemological and Didactic Studies Line in Physical Education during its 15 years of existence within 50 years of CEFD/UFSM. In particular, we will describe its objectives and history, as well the theoretical and pedagogical assumptions that guide its activities. These are in line with the university triad: research, extension and teaching, in the light of the theoretical contributions of Historical and Dialectical Materialism, Historical-Critical Pedagogy, Critical-Overcoming Pedagogy and Corporal Culture in the clash with the irrationalist and relativistic propositions of postmodern theses that permeate the area in contemporary times. In this direction, the Line actions, manifested in a political and scientific way, committed to socialist values, are capable of human and social transformation, because the content of this change is based on scientific knowledge objectified in a new social practice.
\end{abstract}

Keywords: Physical Education; Corporal Culture; Historical Materialism

\footnotetext{
${ }^{\text {I }}$ Universidade Federal de Santa Maria - UFSM - Endereço: Av. Roraima, número 1000, Bairro: Camobi, Prédio 51, Santa Maria, RS. CEP: $97105-900$ - email: gjscapin@gmail.com

${ }^{\text {II }}$ Universidade Federal de Santa Maria - UFSM - e-mail: gabrielquarairsbrasil@gmail.com

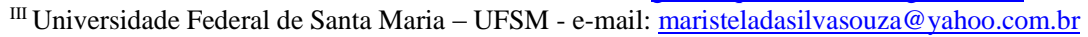




\section{Resumen}

Pretendemos describir y situar la Línea de Estudios Epistemológicos y Didácticos en Educación Física durante sus 15 años de existencia en los 50 años de CEFD/UFSM. En concreto, daremos a conocer sus objetivos y su histórico, así como los supuestos teóricos y pedagógicos que guían sus actividades. Estos están en línea con la tríada universitaria: investigación, extensión y enseñanza, a la luz de los aportes teóricos del materialismo histórico y dialéctico, de la pedagogía histórico-crítica, de la pedagogía crítica-superadora y de la cultura corporal en el choque con las proposiciones irracionalistas y relativistas de las tesis posmodernas que impregnan el área en los tiempos contemporáneos. En esta dirección, las acciones del grupo, manifestadas de manera política y científica, comprometidas con los valores socialistas, son capaces de transformación humana y social, ya que el contenido de este cambio se basa en el conocimiento científico objetivado en una nueva práctica social.

Palabras clave: Educación Física; Cultura Corporal; Materialismo Histórico

\section{Introdução}

Contribuindo com a elaboração do dossiê comemorativo em despeito ao cinquentenário do Centro de Educação Física e Desportos da Universidade Federal de Santa Maria - CEFD/UFSM, elaboramos o presente artigo com o objetivo de descrever e situar a Linha de Estudos Epistemológicos e Didáticos em Educação Física (LEEDEF) durante seus 15 anos de existência produzidos no interior do CEFD/UFSM. Em específico, descreveremos os objetivos e o histórico da Linha, bem como seus pressupostos teóricos de fundamentação.

Dito isso, passamos de imediato à apresentação dos objetivos da referida Linha de estudos, os quais citamos: a) instrumentalizar acadêmicos e professores sobre as tendências epistemológicas do conhecimento científico e sobre os parâmetros didáticos que orientam as práticas pedagógicas em EF; b) estabelecer um trabalho indissociável entre ensino, pesquisa e extensão numa relação dialética entre universidade e comunidade; c) desenvolver ações que materializem intercâmbios com instituições de ensino e linhas de pesquisas, através de estudos, pesquisas, seminários, debates e eventos científicos, tendo em vista um trabalho de produção coletiva em torno de questões que afetam diretamente o ensino e a pesquisa em EF; d) articular projetos de iniciação científica e projetos de pós-graduação, com o fim de produzir e socializar conhecimentos através de publicações em periódicos e livros, atendendo o contexto da comunicação científica; e) estabelecer trocas de conhecimentos com os movimentos sociais, em especial com o MNCR (Movimento Nacional Contra a Regulamentação da Profissão), ExNEEF (Executiva Nacional dos Estudantes de Educação Física) e MST (Movimento dos Trabalhadores Rurais Sem Terra), no sentido de firmar um horizonte histórico socialista, onde educação, ciência e tecnologia exerçam um papel estratégico para esse fim. 


\section{A Gênese da LEEDEF}

Entendemos como necessário apresentar a LEEDEF no movimento histórico do CEFD, pois no ano em que este centro completa 50 anos de existência na UFSM, a LEEDEF completa 15 anos, expressando juntamente com o CEFD, o seu compromisso com o ensino, a pesquisa e a extensão.

Sua gênese, como forma de instauração dos primeiros delineamentos do grupo de trabalho, remete-se ao ano de 1993, a partir da afirmação de um compromisso entre o CEFD/UFSM e a comunidade de Santa Maria através do Projeto Universidade - Comunidade (PUNICOM). No referido projeto, um grupo de professores e acadêmicos do CEFD/UFSM oferecia a crianças e adolescentes possibilidades pedagógicas no âmbito da Cultura Corporal, contribuindo para a formação e emancipação humana.

No ano de 1997, o PUNICON iniciou um vínculo com a Secretaria Nacional de Esportes (SNE), especificamente, com o Programa Esporte Educacional. Nesse contexto de parceria, a denominação do projeto passou a ser: "Projeto Esporte Educacional em Comunidade de Baixa Renda da Cidade de Santa Maria: Jogos Cooperativos". Em 1998, amplia-se o projeto, possibilitando a inserção de outras áreas de conhecimento como Agronomia, Artes Plásticas, Medicina, Odontologia e Pedagogia. Desde então, com a denominação de Projeto Criança Cidadã (PCC), passou a fundamentar-se pelo pressuposto teórico da fenomenologia-hermenêutica, sob orientação da professora Ingrid Marianne Baecker e coordenação da professora Luciana Homerich e, posteriormente, pelo professor Wilton Orlando Trapp (SOUZA et al., 2015).

A partir do ano de 1999, o projeto passa a ser coordenado pela professora Maristela da Silva Souza. Desde então, várias questões foram sendo problematizadas no grupo de trabalho, dentre elas o projeto histórico que se pretendia estabelecer. Essas respostas foram sendo encontradas na teoria social do Materialismo Histórico e Dialético (MHD), que desde então, passou a fundamentar o projeto. Em 2001, a parceria entre o Projeto Criança Cidadã e a Secretaria Nacional de Esportes foi interrompida em decorrência de corte orçamentário que, somado ao descredenciamento do Programa de Pós-graduação do CEFD, causou dificuldades para o desenvolvimento do projeto, já que levou várias pessoas participantes do mesmo a continuar seus estudos e lutas em outras instituições.

O projeto restringiu-se a um grupo de acadêmicos e professores que, com o apoio do CEFD, continuaram a desenvolver as atividades de ensino, pesquisa e extensão. O grupo de trabalho novamente reestruturou-se e, em 2005, criou-se a LEEDEF, sob a coordenação da professora Maristela da Silva Souza, que neste mesmo ano, também passou a ser docente deste centro. Com a criação do Curso de 
Bacharelado em EF e a participação de Acadêmicos do mesmo, ampliou-se o campo de estudo da Linha que estava exclusivamente direcionado para o âmbito da escola. Assim, a LEEDEF representa hoje uma síntese de tudo o que foi coletivamente produzido em anos de trabalho, e que podemos considerar como mais um ponto de partida para novos saltos qualitativos rumo à construção de um projeto histórico socialista pautado pelos princípios e pressupostos mencionados a seguir.

\section{Aspectos Teórico-Filosóficos e Pedagógico-Metodológicos da LEEDEF}

O que segue, demonstra os pressupostos teóricos nos quais a LEEDEF se sustenta, ou seja, o pressuposto teórico do MHD, a Pedagogia Histórico-Crítica, a Pedagogia Crítico-Superadora e a Cultura Corporal na qualidade de objeto de conhecimento da área. Esta fundamentação procura elucidar as concepções de conhecimento, educação, sujeito, EF que juntas e, de maneira indissociadas, constituem a visão de mundo e totalidade da referida Linha.

Nosso ponto de partida é a relação sujeito e natureza no processo de construção do gênero humana na perspectiva marxista. Segundo Andery; Sério (1999), Marx influenciou-se nos ideais hegelianos de esquerda, que procuravam situar o papel crítico da filosofia, concebendo o homem como sujeito e como um ser consciente e ativo. Feuerbach, pertencente a esse grupo, através de sua concepção materialista de sujeito, também influenciou Marx, pois:

\footnotetext{
[reconstruiu] o conceito de alienação: o homem aliena-se ao atribuir a entidades, que são criações suas, qualidades e poderes que, na verdade, pertencem ao próprio homem. Com essa crítica, Feuerbach expressa uma concepção materialista e naturalista do homem, em vez da concepção idealista proposta por Hegel (ANDERY; SÉRIO, 1999, p. 398).
}

Em um dos aspectos fundamentais de sua proposta para a produção de conhecimento, Marx pautado pela perspectiva Feuerbachiana, afirma que, ao contrário de Hegel, os sujeitos constroem e recriam suas ideias a partir de sua interação com a natureza. Portanto, Marx concebe a matéria como algo que existe fora da consciência, independentemente dela. As ideias, portanto, são "[...] o material transposto para, traduzido pela consciência humana" (idem, p. 402), visto que é o ser social do homem que determina sua consciência (MARX, 2008).

O fato de Marx estabelecer o ser social como determinante da consciência do ser humano (ponto de partida materialista/concreto) afasta-o e contrapõe-se a Hegel (ponto de partida idealista/abstrato), que vê o sujeito como criação do Espírito Absoluto. Em 'A Ideologia Alemã' encontramos algumas passagens referentes a essa perspectiva materialista: 
A produção de ideias, de representações, da consciência, está, de início, diretamente entrelaçada com a atividade material e com o intercâmbio material dos homens, como a linguagem da vida real. O representar, o pensar, o intercâmbio espiritual dos homens, aparecem aqui como emanação direta de seu comportamento material. (...) a consciência jamais pode ser outra coisa do que o ser consciente, e o ser dos homens é o seu processo de vida real. (...) os homens, ao desenvolverem sua produção material e seu intercâmbio material, transformam também, com esta sua realidade, seu pensar e os produtos do seu pensar. Não é a consciência que determina a vida, mas a vida que determina a consciência (MARX; ENGELS, 2010, p. 51).

Segundo Marx (1978, p. 11-12), as “[...] ações humanas [ouvir, ver, cheirar, etc] como relações humanas com o mundo [...]" constroem e desenvolvem o sujeito tanto biológica ("aparato perceptivo") quanto psicologicamente (“sentidos 'práticos e espirituais"”), negando, a partir dessa definição, uma ideia de natureza humana "[...] pronta, imutável, resultado de algo exterior e independente do próprio ser. Supõe a necessidade de um homem ativo na construção de si mesmo, da natureza ou de sua história, de um homem envolvido num processo contínuo e infinito de construção de si mesmo".

Para Gramsci, o conceito de sujeito se constitui em uma "[...] série de relações ativas (um processo), no qual, se a individualidade tem a máxima importância, não é, todavia o único elemento a ser considerado" (1978, p. 39). O sujeito, portanto, entra em relações com a natureza e com os outros sujeitos ativamente, pelo trabalho e pela técnica (conhecimento teórico-científico). Essas relações “[...] são ativas e conscientes, ou seja, correspondem a um grau maior ou menor de inteligibilidade que delas tenha o homem individual". Assim, cada sujeito transforma e modifica a si mesmo "[...] na medida em que transforma e modifica todo o conjunto de relações do qual é o ponto central” (1978, p. 40).

Contudo, não é suficiente conhecer o conjunto das relações enquanto existentes em um dado momento como um dado sistema, “[...] importa conhecê-los [geneticamente], em seu movimento de formação, já que todo indivíduo é não [somente] a síntese das relações existentes, mas também da história destas relações, isto é, o resumo de todo o passado". Nesse sentido, a "“natureza humana' é o 'conjunto das relações sociais"”. Para Gramsci, essa afirmação é a mais satisfatória porque inclui a ideia de mudança, de transformação contínua das relações sociais; e, também, porque nega “[...] o homem em geral: de fato, as relações sociais são expressas por diversos grupos de homens que se pressupõem uns aos outros, cuja unidade é dialética e não formal”' (Gramsci, 1978, p. 40-43).

Para Marx, o sujeito faz parte da natureza, entretanto não se confunde com ela,

O homem é um ser natural porque foi criado pela própria natureza, porque depende da natureza, de sua transformação, para sobreviver. Por outro lado, o homem não se confunde com a natureza, o homem diferencia-se da natureza, já que [a] usa [...] transformando-a conscientemente segundo suas necessidades e, nesse processo, faz-se homem. Assim, Marx, a um só tempo, identifica e distingue homem e natureza, e naturaliza e humaniza o homem e a natureza (ANDERY; SÉRIO,1999, p. 403). 
Assim, para compreender o sujeito devemos percebê-lo na sua interação com a natureza, já que é através dela que o humano deixa de ser um produto puro para se forjar um produtor ativo do que o produz. A natureza representa a estrutura inorgânica do ser humano, isto é, não é ela mesma o ser humano, mas é uma base para sua existência e "[...] a vida física e espiritual do homem está ligada com a natureza [...], a natureza está ligada consigo mesma, pois o homem é uma parte da natureza. O homem [...] tem atividade vital consciente. Esta distingue-o imediatamente da atividade vital animal" (ANDERY; SÉRIO, 1999, p. 404).

O sujeito, conforme explicam Andery; Sério (1999, p. 404), é compreendido por Marx como ser genérico, isto é, “[...] como ser que opera sobre o mundo, sobre os outros sujeitos e sobre si mesmo, enquanto gênero, enquanto espécie que busca sua sobrevivência”. Contudo, o sujeito não se limita apenas à sobrevivência, ele busca transformar a sociedade e a natureza e sente-se capaz de fazê-lo “[...] porque se reconhece e reconhece ao outro nesse processo".

A distinção do humano em relação aos demais animais se deve a atividade produtiva consciente, ou nas palavras de Marx; Engels (2010) na capacidade de fazer história, que demanda considerar quatro facetas relações históricas, a saber: 1) produção de meios para a satisfação de necessidade imediatas (comer, beber, habitar, vestir); 2) a satisfação das primeiras necessidades e a incorporação dos seus instrumentos, que criam novas necessidades humanas; 3) renovação e reprodução da vida, germe da família e posteriormente das relações sociais; 4) associação dialética da relação natural com a relação social conduzem o homem a criar um determinado modo de cooperação (através do trabalho) entre os humanos, que condiciona as relações sociais e, por conseguinte, da humanidade.

O sujeito trabalha, transforma a natureza (e a si mesmo, por consequência) para satisfazer suas necessidades materiais e espirituais - que se transformam num processo histórico - as quais também podem ser recriadas pelo sujeito através desse trabalho. As necessidades, ao serem criadas e transformadas, não seguem uma mesma direção, podendo ocorrer em direções opostas, num mesmo momento. Na sociedade capitalista, por exemplo, ocorre um refinamento das necessidades para alguns e um embrutecimento das mesmas para outros. O movimento dessas necessidades humanas reflete "[...] as condições objetivas de um determinado momento histórico [...]” e, nesse sentido, suas contradições (ANDERY; SÉRIO, 1999, p. 407). Se essas necessidades e seus meios se aperfeiçoam por um lado e se brutalizam por outro, ocorre um processo de alienação, onde o trabalhador aparece desprovido das condições materiais de vida (idem, 1999, p. 408).

Os homens produzem princípios, ideias, enfim, conhecimento, a partir de suas relações sociais, estabelecidas de acordo com sua produtividade material. Por expressar o real (mutável e transitório), o 
conhecimento é um produto histórico e provisório. Assim, o conhecimento se desenvolve no movimento de contradições e num eterno fazer e refazer, onde a ciência e o pensamento elaborado deve elucidar tal representação antagônica como forma de possibilitar a compreensão da realidade em sua concretude objetiva.

Nesse sentido, Marx (2008, p. 260) afirma que “[...] o concreto é concreto porque é a síntese de muitas determinações, isto é, unidade do diverso". Para se compreender os fenômenos (concreto) em sua totalidade, o processo de compreensão, em Marx, deve partir da representação caótica do todo, que por meio de uma determinação mais estrita e analítica conduz o sujeito à conceitos mais simples do concreto representado, chegando a abstrações mais tênues, alçando as determinações mais simples, necessitando fazer o caminho inverso, entretanto com uma diferença qualitativa da representação caótica do todo, ou seja, detendo um rica totalidade de relações e determinações (MARX, 2008).

Em síntese, o sujeito do conhecimento, na relação ser humano e natureza, possui a tarefa de desvelar e estabelecer as determinações históricas e concretas. Esse processo, o qual pauta as relações acadêmico-científicas e produtivas da LEEDEF, se dará a partir da análise do fenômeno concreto e objetivo, o qual será reconstruído no pensamento, isto é, reconstruído como fenômeno concretopensando.

\subsection{Educação: método da passagem do Concreto-Empírico ao Concreto-Pensado}

A LEEDEF parte do pressuposto de que toda a criança e adolescente tem direito à educação e, através dessa, o direito a superar o senso comum e a apropriar-se do saber universal acumulado históricasocialmente, capacitando-se a produzir conhecimento novo e necessário para transformar o sentir, o ver, o pensar e o fazer a vida e o mundo rumo à igualdade humana. Dominar o conhecimento deve, portanto, significar o desafio e o encorajamento de cada um para que seja sujeito histórico de um projeto que aponte no sentido da superação das desigualdades. Para isso é necessário o entendimento de igualdade em termos reais e concretos, não apenas formais, no qual a pedagogia, em especial, a Pedagogia HistóricoCrítica, busca converter-se, articulando-se com as forças emergentes da sociedade, em instrumento a serviço da instauração de uma sociedade igualitária (SAVIANI, 2012).

Entendemos a Educação na totalidade da prática histórico-social, que é toda ela educativa e formadora do sujeito-cidadão. Sujeito que se constrói não só do meio, nem de potencialidades inatas. O ser humano, na compreensão do MHD, interage com o meio numa relação constante entre os fatores internos e externos, de forma que interferem mutuamente entre si, isto é, enquanto o sujeito age sobre a 
natureza esse a modifica ao mesmo tempo em que a natureza exerce influência sobre o ser humano, organismo e meio exercem ação recíproca.

Nesta perspectiva, Vigotski (1999) visualizou nos princípios do MHD a solução dos modelos científicos fundamentais com que se defrontavam seus contemporâneos. Um ponto central desses princípios é que todos os fenômenos sejam estudados como processos em movimento e em mudança. Dessa forma, para estudar o processo de desenvolvimento intelectual do sujeito não se deve partir de seu pensamento, mas sim da atividade de vida real desse sujeito, isto é, do mundo objetivo. Todo o fenômeno tem sua história, e como essa história é caracterizada por mudanças qualitativas e quantitativas, Vigotski aplicou essa linha de raciocínio para explicar a transformação dos processos psicológicos elementares em processos complexos ou superiores.

Para ele, na relação entre sujeito e natureza, existe o controle da natureza por meio dos instrumentos de trabalho e o controle do comportamento por meio do uso de signos. No emprego dos signos (linguagem, escrita, sistema de números, etc) e a relação desses com os valores, crenças, cultura e ciência, Vigotski destaca a linguagem, decorrente ao papel que exerce na organização e desenvolvimento histórico dos processos de conhecimento. Portanto, é na interação entre signos (principalmente a linguagem) e o pensamento é que se desencadeia o processo de produção de novos conhecimentos no sujeito. Do mesmo modo, modificam-se as estruturas do pensamento que lhe possibilitam a apropriação de novos conhecimentos, é isso, por fim, que Vigotski denomina de processos superiores ou formas elaboradas de comportamento.

Corroborando Saviani (2013), reitera que cabe à educação elevar, nos educandos, o nível do senso comum ao nível da consciência filosófica, o que significa passar de um conhecimento fragmentado, incoerente e simplista para um conhecimento unitário, coerente e cultivado. Conforme o autor, a realização dessa tarefa deve ser concretiza através do método proposto por Marx, que emprega a lógica Dialética no processo de construção da forma de pensamento, superando por inclusão/incorporação a Lógica Formal, que se caracteriza como a parte inicial, onde apenas se fará o processo abstracional e não se fará o caminho de volta que é o ponto principal do método dialético. Portanto, a construção do conhecimento se dá partindo do empírico, passando pelo abstrato e chegando ao concreto. O concreto é ao mesmo tempo o ponto de partida e o de chegada, sendo que o concreto como ponto de partida é o concreto-empírico e o concreto como ponto de chegada é o concreto-pensado. Aqui o empírico e o abstrato são meros passos para nos apropriarmos, no plano do pensamento, do ponto principal que é o concreto pensando e elaborado. 
Nesse viés, os pressupostos metodológicos e pedagógicos que pautam as ações de ensino da LEEDEF partem da ascensão do empírico ao concreto, conforme os cinco passos propostos por Saviani (2012), no qual se inicia pela prática social (conhecimento caótico do todo) - problematização (contradições) - instrumentalização (apropriação do conhecimento historicamente acumulado) - catarse (totalidade - conhecimento mais elaborado) - prática social (concreto pensado). Lembrando que esse é um caminho pelo devamos estabelecer, que é o caminho de ida e de volta, que se dá através da dialética materialista, partindo do concreto-empírico ao concreto-pensado, mediado pelas análises e abstrações no plano do pensamento.

\subsection{Educação Física: O trato com a Cultura Corporal}

Para findarmos esse item, resta-nos apresentar os pressupostos que estabelecem as bases de materialização e socialização do objeto da EF manifestado no plano da Cultura Corporal e tematizado à luz da Pedagogia Crítico-Superadora.

Historicamente, a EF Escolar Brasileira teve a influência de diversas correntes filosóficas, sobretudo, de base positivista. Na década de 70, a partir do decreto ${ }^{\circ} 69.450$ de 1971, a EF passou a ser considerada uma atividade, que "[...] por seus meios, processos e técnicas, desenvolve e aprimora forças físicas, morais, cívicas, psíquicas e sociais do educando”, enfatizando, a partir dessa, a aptidão física. A partir da década de 80, no interior de uma crise de paradigma, possibilitou a inserção de novas tendências que atribuíam à escola a função de não simplesmente promover o rendimento técnico, mas proporcionar uma discussão sob o prisma das teorias críticas da área. Essa discussão se alicerçou e se ampliou a partir da Lei de Diretrizes e Bases da Educação Nacional n 9.394/96, que estabeleceu para a área a condição de componente curricular obrigatório dos currículos escolares.

Dentre as teorias críticas da área, pautada pelo MHD e elaborada por um Coletivo de Autores nas décadas de 1980/90, está a Pedagogia Crítico-Superadora. Essa abordagem está intimamente comprometida com as transformações sociais, políticas e econômicas, onde se propõe a superação das desigualdades sociais possibilitando a compreensão, por parte dos alunos e das alunas, de que a EF está fortemente interligada com toda dinâmica humana. Portanto, a EF não trata de qualquer movimento e sim do movimento que se constitui nos âmbitos dos saberes populares, das ciências (Humanas e Naturais) e da cultura (COLETIVO DE AUTORES, 2012). 
Para o Coletivo de Autores, que situa a Cultura Corporal como objeto de conhecimento da área, a Pedagogia Crítico-Superadora possibilita o entendimento da concepção de homem e realidade dentro de uma visão de totalidade e, ao ser tratada no ambiente escolar, integrada ao currículo:

Busca desenvolver uma reflexão pedagógica sobre o acervo de formas de representação do mundo que o homem tem produzido no decorrer da história, exteriorizadas pela expressão corporal: jogos, danças, lutas, exercícios ginásticos, esporte, malabarismo, contorcionismo, mímica e outros, que podem ser identificados como formas de representação simbólica de realidades vividas pelo homem, historicamente criadas e culturalmente desenvolvidas. (Idem, p. 39).

Ainda sobre a perspectiva do Coletivo de Autores (2012, p. 41) e da Pedagogia CríticoSuperadora, a EF escolar possui como finalidade a emancipação humana, alinhada aos interesses da classe trabalhadora:

A expectativa da Educação Física escolar, que tem como objeto a reflexão sobre a Cultura Corporal, contribui para a afirmação dos interesses de classe das camadas populares, na medida em que desenvolve uma reflexão pedagógica sobre os valores como solidariedade substituindo individualismo, cooperação confrontando a disputa, distribuição em confronto com a apropriação, sobretudo enfatizando a liberdade de expressão de movimentos - a emancipação -, negando a dominação e submissão do homem pelo homem.

Para, pois, sustentarmos a materialidade da Cultura Corporal à luz da referida pedagogia e enquanto objeto da EF, devemos atentarmo-nos ao seu papel social nas relações humanas e culturais. Nesse sentido, a LEEDEF, como um grupo de trabalho articulado e perspectivando um horizonte crítico e emancipado para a formação humana, entende que a função da EF está explicitamente vinculada às necessidades do coletivo social para projetar um determinado projeto histórico de sociedade, estabelecido por uma forma de conhecimento utilizado para assegurar suas bases de ampliação e emancipação humana.

A Cultura Corporal, como objeto da prática pedagógica da EF e da forma como a referida Linha fundamenta suas ações pedagógicas, utiliza como conhecimento, para o processo de transformação social e histórico, diversos temas: a ginástica, o esporte, o jogo, a dança, as lutas, acrobacias, as brincadeiras populares, entre outras; relacionando-os com os principais problemas tanto da dimensão corporal como do contexto histórico-social dos alunos, desenvolvendo a criatividade, a consciência política, a autodeterminação e a coletividade.

Escobar (2012) situa a Cultura Corporal enquanto parte da cultura objetivada no agir humano, na transformação coletiva do mundo a partir do trabalho. A autora destaca a categoria atividade humana como central, situando o "agir" no seu entendimento:

A categoria atividade humana, chamada categoria porque é uma explicação do que o homem faz, indica que o homem não se move, não se mexe a toa, não podemos falar do movimento do homem, da vida do movimento do homem, isto e um equívoco porque o homem não se mexe, ele 
"age". É diferente agir do que se mexer. "Atividade" e "movimento" são conceitos diferentes. Quando o homem tem que resolver um problema, ele tem que organizar todo um complexo de atividades para resolvê-lo. As ações que ele realiza, e que podem ser vistas de fora, não podem ser reduzidas à simples repetição de movimentos de flexão, extensão, torção, adução, abdução e outras, porque a atividade humana é um complexo de ação, pensamento e emoção desencadeado por objetivos que não se colocam de fora (ESCOBAR, 2012, p.128, grifo nosso).

O agir corporal - sistematizado e manifestado na forma de cultura e conhecimento - constitui a materialidade corpórea da EF estabelecida na análise, estudo e apropriação da Cultura Corporal socialmente produzida e historicamente acumulada pela humanidade como forma de patrimônio cultural da humanidade. Ademais, possui, portanto, a necessidade de ser transmitida às novas gerações na forma de conteúdos de ensino com a intenção de complementar a totalidade humana de cada indivíduo.

Nesse sentido, concordamos com Souza (2009) ao corroborar essa afirmativa quando evidencia que a apreensão da cultura, manifestada no agir corporal sistematizado historicamente, possibilita ao sujeito compreender-se numa perspectiva histórico-cultural, pois:

Foi com o objetivo de fazer e possuir cultura que homens e mulheres, sob um processo de aprendizado, apreenderam a natureza transformando-a em patrimônio cultural. Desta forma, a expressão corporal deve ser refletida que o sujeito consiga compreender-se e compreender a realidade numa visão histórico-cultural. (idem, p. 83).

Por fim, a Cultura Corporal, não se limitando a uma linguagem corporal, se constitui e se manifesta a partir da atividade humana consciente, fruto do trabalho humano, ou seja, a EF enquanto prática corporal sistematizada histórica-socialmente é uma atividade humana porque é uma explicação do que o homem faz a partir do agir corporal no âmbito da cultura.

\section{Considerações Finais}

Realizada a descrição dos objetivos, histórico e aportes teóricos que sustentam as atividades da LEEDEF, vale destacar, à guisa de palavras finais, os projetos e ações que a Linha produziu e oferta à comunidade acadêmica. No que se refere: a) ensino: com o desenvolvimento de práticas pedagógicas que vinculam universidade e escola com a finalidade de proporcionar e incentivar a iniciação à docência e qualificar a formação inicial de professores de EF. Citamos, como exemplo, o Programa Institucional de Bolsas de Iniciação à Docência (PIBID); b) extensão: com ações que tematizam as práticas corporais da Cultura Corporal em escolas e em locais comunitários da região de Santa Maria - RS. Citamos, como exemplo, os projetos "Experienciando a ginástica na escola enquanto possibilidade superadora no plano 
da Cultura Corporal" e "Processo de Formação Continuada: ações entre o CEFD-UFSM e os professores de Educação Física da Quarta Colônia - RS"; c) pesquisa: com projetos e orientações de pesquisas, até então concluídas, em nível de graduação (08), especialização (22) e mestrado acadêmico (21).

Também é oportuno salientar a vasta produção acadêmico-científica da Linha socializada em publicações de periódicos da área da Educação Física na modalidade de artigo completo (39), bem como em formato de capítulos de livros (19) e livro (02). Da mesma forma mencionamos a organização de eventos empreendida pela Linha, uma vez que protagonizou a preparação de seminários (04) acadêmicocientíficos para o público alvo da área. Dentre eles citamos: "IV Seminário em Epistemologia e Educação Física e II Seminários em Formação de Professores”, realizado em 2013.

Por fim, reiteramos a pertinência da existência da LEEDEF enquanto grupo de estudo e de trabalho acadêmico-científico à luz dos aportes teóricos do MHD, da Pedagogia Histórico-Crítica, da Pedagogia Crítico-Superadora e da Cultura Corporal, diante das proposições irracionalistas e relativistas das teses pós-modernas que permeiam a área neste movimento histórico contemporâneo. Faz-se necessário, portanto, assumirmos o enfrentamento político/ideológico que esse contexto nos trás e que indica um momento complexo e particular no desenvolvimento da sociedade como um todo.

Defendemos ser necessária uma leitura crítica e apurada da realidade para assumirmos uma posição política/pedagógica frente ao ato educativo e formativo. Isso implica em entendermos os caminhos do conhecimento e seus projetos históricos que se anunciam nas concepções pedagógicas e científicas, que trazem visões de mundo diferentes e estabelecem formas contraditórias de pensar e agir nas práticas sociais. Nessa direção, as ações da LEEDEF, manifestadas de maneira política e científica, comprometidas com valores socialistas, são capazes de transformação humana e social. A primeira tarefa estabelecida pela Linha é a mudança das consciências alicerçada no conhecimento científico e concretizado numa nova prática social que não flerta com o senso comum, com os relativismos e irracionalismos pós-modernos.

\section{Referências}

ANDERY, M. A.; SÉRIO, T. M. A prática, a história e a construção do conhecimento: Karl Marx. In: ANDERY, et al. Para compreender a ciência: uma perspectiva histórica. São Paulo/Rio de Janeiro: Espaço e tempo, 1999.

BRASIL. Lei n. 9.394, de 20 de dezembro de 1996. Estabelece as diretrizes e bases da educação nacional. Disponível em: http://www.planalto.gov.br/ccivil_03/leis/L9394.htm. Acesso em: 20 jun. 2020. 
Decreto $\mathrm{n}^{\circ} 69.450$ de 1 de novembro 1971. Regulamenta o art. 22 da Lei $\mathrm{n}^{\circ} 4.024$, de 20 de dezembro de 1961, e a alínea "C" do art.40 da Lei n 5.540, de 28 de novembro de 1968, e dá outras providências. Brasília, DF. Disponível em: http://www.presidencia.gov.br/. Acesso em: 20 jun. 2020.

COLETIVO DE AUTORES. Metodologia do ensino da Educação Física. 2ed. ver. São Paulo: Cortez, 2012.

ESCOBAR, M. O.. Coletivo de Autores: a Cultura Corporal em questão. In: COLETIVO DE AUTORES. Metodologia do Ensino de Educação Física. - 3 ${ }^{\text {a }}$ reimp., 2 2 ed.rev.- Sao Paulo: Cortez, 2012.

GRAMSCI, A. Os intelectuais e a organização da cultura. Rio de Janeiro: Civilização Brasileira, 1978.

MARX, Karl. O Capital: Capítulo VI (inédito). São Paulo: LECH, 1978.

Contribuição à crítica da economia política. 2ed. - São Paulo: Expressão Popular, 2008.

MARX, K.; ENGELS, F. A Ideologia Alemã. 3.reimp. São Paulo: Martin Claret, 2010.

SAVIANI, D. Escola e Democracia. 42a ed. Campinas, SP: Autores Associados, 2012.

Educação: do senso comum à consciência filosófica. - 19. Ed. - Campinas, SP: Autores Associados, 2013.

SOUZA, M. Esporte Escolar: possibilidade superadora no plano da cultura corporal. São Paulo: Ícone, 2009.

SOUZA et.al. Linha de Estudos Epistemológicos e Didáticos da Educação Física (LEEDEF): o compromisso no processo de ensino, pesquisa e extensão na relação entre Educação Física e o Mundo do Trabalho. In SOUZA, M. S.; RIBAS, J. F. M.; CALHEIROS, V. C (orgs). Conhecimento em Educação Física: no movimento das mudanças, no mundo do trabalho. Santa Maria: Editora UFSM, 2015.

VYGOTSKY, L. S. A formação social da mente. São Paulo: Martins Fontes, 1999.

\section{Como citar este artigo}

SCAPIN, G. J.; GOMES, G. V.; SOUZA, M. S. Os 15 anos da Linha de Estudos Epistemológicos de Didáticos em Educação Física no cinquentenário do Centro de Educação Física e Desportos da UFSM. Revista Kinesis, Santa Maria, Dossiê CEFD 50 anos, p.01-13, 2020.

* O presente trabalho não contou com apoio financeiro de nenhuma natureza para sua realização. 